\title{
LA SOLANA DEL CASTILLO DE ALANGE: UN YACIMIENTO DE LA EDAD DEL BRONCE EN LA CUENCA MEDIA DEL GUADIANA ${ }^{1}$
}

\author{
THE SOLANA DEL CASTILLO DE ALANGE: A BRONZE AGE \\ SITE IN THE MIDDLE GUADIANA BASIN
}

\author{
por \\ IGNACIO PAVÓN SOLDEVILA
}

\begin{abstract}
RESUMEN: El estudio del yacimiento de La Solana del Castillo de Alange ofrece ciertas pautas para la comprensión del segundo milenio A.C en la Cuenca Media del Guadiana, a través tanto de una propuesta de secuencia cultural de la Edad del Bronce como de un intento de reconstrucción de las bases subsistenciales de aquella sociedad.

Palabras clave: Cuenca Media del Guadiana, Epicalcolítico, Bronce Medio, Bronce Final.
\end{abstract}

\begin{abstract}
The study of The Solana, in Alange's Castle, offers some models for the understanding of the 2nd millenium B.C. in the Guadiana Middle Basin, accross a proposal of cultural sequence from the Bronze Age as an intent of rebuilding of the subsistences aspects of that society.
\end{abstract}

A pesar de que el conocimiento de la Prehistoria Reciente en la Cuenca Media del Guadiana ha experimentado en los últimos años un crecimiento importante, los comportamientos culturales y subsistenciales de los grupos humanos continúan siendo especialmente mal conocidos en algunas de sus etapas (Enríquez y Hurtado, 1986). Tal es el caso de la Edad del Bronce. Sin embargo, en modo alguno se puede decir que dicha laguna de conocimientos sea exclusiva de la geografía bajoextremeña, sino que afecta globalmente a ese personalizado mundo del Suroeste en el cual se incluye.

Los primeros intentos de esclarecimiento de este interrogante fueron llevados a cabo por Schubart desde mediados de los años sesenta (Schubart, 1968), y cristalizaron en una interpretación de la denominada «Cultura de Atalaia» (Schubart, 1974 y 1975) que ha servido para articular no sólo las

1. El presente artículo es un resumen de la Tesis de Licenciatura del autor, dirigida por el Dr. Rodríguez Díaz, Profesor Titular de la UNEX., y defendida en junio de 1992 en la Universidad de Extremadura. 
manifestaciones documentadas en el Algarve y el Alentejo, sino también, y de un modo provisional, las evidencias dispersas de la zona más occidental de Andalucía y de la provincia de Badajoz. En la primera mitad de los ochenta, las estratigrafías de La Mesa de Setefilla (Lora del Río, Sevilla) (Aubet, 1983) y Monte Berrueco (Medina Sidonia, Cádiz) (Escacena y De Frutos, 1985) resucitaron el interés por llevar a cabo una interpretación de la Edad del Bronce en el Bajo Guadalquivir, en tanto que a comienzos de la presente década Hurtado (1991) retomaba la senda de los trabajos emprendidos por M. Del Amo en los setenta (Del Amo, 1975), al adentrarse en el estudio de las sociedades prehistóricas de la Sierra de Huelva.

El panorama que ofrecía hasta hoy la Baja Extremadura durante su Edad del Bronce resultaba tremendamente etéreo puesto que no sólo se carecía de cualquier información relativa al tipo de hábitat y a los modos de vida, sino que también las manifestaciones funerarias presentaban una problemática interpretación, derivada en no pocos casos de la confusión que parecía introducir su relación espacial con poblados de sabor epicalcolítico (Gil-Mascarell y otros, 1986).

En el año 1987, con motivo de la realización de las obras de infraestructura que acompañaban a la construcción de la presa del pantano de Alange (Badajoz), se produjo la destrucción parcial de un poblado asentado en la ladera de la solana del castillo de Alange (Calero y otros, 1988; Calero y Márquez, 1992). La excavación de urgencia llevada a cabo por D. José Angel Calero Carretero, director del Plan Especial de intervenciones arqueológicas en Alange, en el verano de dicho año, supuso la extracción sistemática de una serie de materiales que nos fueron gentilmente cedidos para su estudio. El presente artículo es un resumen de dicho trabajo.

\section{MARCO GEOGRÁFICO Y LOCALIZACIÓN}

El poblado asentado en la falda de la solana del Castillo de Alange presenta interesantes aspectos geográficos que deben conocerse para entender su dinámica, y entre los cuales destacamos dos.

En primer lugar debe resaltarse su emplazamiento en el «monte-isla» (485 m. s.n.m.) más importante situado a medio camino entre las Vegas Altas y Bajas del Guadiana (Fig 1), que además goza de control visual sobre los dos vados principales de la comarca de Mérida, como son el de la estación de Zarza de Alange y el de Los Patos. El papel que la historiografía ha concedido a Mérida como cruce de caminos a raíz de la construcción de su puente romano es el mismo que presumiblemente desempeñó el yacimiento de la Solana durante el fin de la Prehistoria y el transcurso de la Protohistoria. Además, a sus pies tiene lugar la confluencia de los ríos Matachel y Palomillas, que unos $5 \mathrm{~km}$. al norte desembocan en el Guadiana; dichos ríos discurren por unas tierras que participan de distintas naturalezas, como es propio de una zona de contacto entre tres áreas morfológicamente distintas, como son el área de los Barros, el del Guadiana y el de la zona granítica emeritense. Característica fundamental de las dos primeras regiones es su aptitud para un floreciente desarrollo de la agricultura, de secano en el primero de los casos, y de regadío en el segundo. En la Tierra de Barros, las deposiciones miocénicas, han dado lugar a suelos franco-arcillosos, muy aptos para la aparición de vegetación adehesada. La ocupación humana posterior introdujo el olivar y el viñedo. En el área del Guadiana, por su parte, los suelos son tremendamente ricos, con un espesor muy amplio. Predominan allí las arcillas y arcosas del Oligoceno, aunque, debido a que los aportes son múltiples, hay insistentes cambios de suelos. En este sentido la abundancia de los suelos franco nos indica la mezcla de distintas texturas, entre las que no predomina ninguna en concreto (arcilla, arena y limos). Se trata, como ya hemos señalado, de tierras con una dedicación plena para el regadío (Guerra Delgado y Monturiol, 1968). 
El «monte-isla» del Cerro del Castillo de Alange presenta en la solana de su falda un amplio poblado, de extensión, no obstante, indeterminada, con una cota para el punto 0 de la excavación de 282, $018 \mathrm{~m}$. s.n.m., por debajo de la cual hay un gran desnivel hasta la unión de los ríos Palomillas y Matachel. El enclave elegido para el asentamiento no es muy accesible, y está perfectamente defendido por crestones de roca. Hasta el momento no se ha localizado muralla alguna que lo delimite, pero no negamos la posibilidad de que exista. Por encima del punto 0 el límite del poblado sí podría situarse en los paredones rocosos que lo cierran al Noreste.

\section{SECUENCIA ESTRATIGRÁFICA}

La metodología empleada durante el proceso de excavación primó el desarrollo de sondeos que permitieran, mediante una lectura estratigráfica, la valoración cultural de la parte del yacimiento afectada, con vistas a tener una referencia que posibilitara sopesar el interés del lugar de cara a futuras intervenciones. Se abrieron cinco cortes, que no evidenciaron restos inequívocos de estructuras, y que presentaron básicamente la misma secuencia estratigráfica, circustancia que ha posibilitado el estudio conjunto de una serie de materiales cerámicos, líticos, óseos y metálicos. También se recuperaron restos de fauna, semillas y escorias metálicas.

El estudio de la industria cerámica ha resultado determinante para precisar la periodización y conología del yacimiento, para valorarlo en relación con el conjunto de datos que hasta hoy teníamos de las etapas terminales de la Prehistoria en la Cuenca Media del Guadiana, y para elaborar una interpretación de la Edad del Bronce en nuestra zona que debe considerarse tan sólo como una hipótesis de trabajo con utilidad provisional. Dicha propuesta se articula en tres horizontes.

En el Horizonte Solana I encontramos ciertos rasgos morfológicos que nos hablan de un muy fuerte grado de «calcolitización», que se concretan cuantitativamente en la documentación de ollas globulares y vasos de paredes rectas en elevados porcentajes. En los momentos finales comienzan a documentarse formas nuevas como las cazuelas carenadas, y se produce la máxima representación porcentual de elementos como los cuencos de borde entrante y los casquetes esféricos. Cualitativamente, los cuencos carenados nos ponen en relación con el mundo de las cerámicas de «paredes delgadas», que parecen tomar el pulso al Calcolítico Final y a la transición hacia el Bronce Pleno. La ausencia de los auténticos estandartes culturales de las fases plena y final del Calcolítico en La Solana, esto es, la no presencia de platos de borde engrosado o almendrado, ni de cerámica decorada campaniforme, nos invita a considerarla una fase culturalmente tardía, que perfectamente podría denominarse «Epicalcolítica». El Horizonte Solana II, adscrito al Bronce Pleno, refleja un momento muy fuertemente personalizado por piezas de perfil carenado que nos ponen en relación con la cultura del Bronce del Suroeste. Finalmente el Horizonte Solana III, que para poder ser valorado medianamente necesita contrastarse con los estudios recientes del Dr. Enríquez Navascués, que, hasta el momento, hacen referencia de los materiales procedentes de la superficie del yacimiento. El abanico cronológico de dichas muestras es amplio, y culturalmente pensamos que podrían aludir tanto al denominado Bronce Tardío como al Bronce Final. 


\subsection{HORIZONTE SOLANA I}

Compuesto por dos conjuntos de materiales aislados por cuestiones metodológicas, incluye el estrato XII y los estratos X al VIII, que globalmente parecen responder al mismo momento cultural (Fig 2).

El estrato XII, desde el punto de vista tecnológico se caracteriza por el dominio aplastante de las cerámicas toscas, seguidas muy de lejos por las semicuidadas, hecho que no impide que en algún caso puntual nos encontremos con los primeros ejemplares cuidados. La existencia de cerámica tosca cocida irregularmente en un porcentaje superior al del resto de los momentos, y muy por encima de los porcentajes que presentan los otros tipos de cocción, es característica. Por lo que respecta a los acabados, predominan de un modo notorio los alisados simples, siendo excepcionalmente raros los bruñidos, aunque sí los constatamos en algunos cortes, tal vez por filtraciones. Personaliza este momento la presencia de espatulados, que continuarán existiendo más adelante. Como siempre en La Solana, el porcentaje de cerámicas decoradas del momento es mínimo.

Morfológicamente es un momento perfectamente caracterizado. Por una parte, las piezas carenadas son casi exclusivamente cuencos $(4,7 \%)$, vinculados principalmente a los documentados en el horizonte en el cual Hurtado (Hurtado, 1985) considera definitorias las piezas de «paredes delgadas». Entre las piezas redondeadas, podemos vislumbrar ya el comienzo del declive de los perfiles en $\mathrm{S}(3,5 \%)$, y auscultamos la presencia de los cuencos de borde entrante $(7,1 \%)$, que veremos desarrollarse en el futuro. Exponente de las tradiciones calcolíticas fuertemente arraigadas en la zona (Enríquez, 1990,1) es el porcentaje de ollas globulares de tamaño mediano $(13 \%)$ y grande $(7,1 \%)$, que comenzarán a sufrir un retroceso a partir de este estrato. También característico de este momento es el alto porcentaje presentado por los vasos de paredes rectas en todas sus versiones $(24,9 \%)$ y el de los grandes bordes cóncavos $(26,1 \%)$, también presentes en el Calcolítico. Consideración interesante para la datación cronológica y cultural del momento es la ausencia de dos fósiles tan definidores como los platos de borde almendrado o engrosado y las decoraciones campaniformes.

Entre los estratos X al VIII, en el marco de la tecnología cerámica, la cerámica tosca sigue siendo la más numerosa, pero la semicuidada experimenta un gran alza, y la cuidada no sólo aparece significativamente, sino que presenta también sus valores más altos en uno de los cortes. Por lo que atañe a las cocciones, lo más sobresaliente es la progresiva disminución porcentual de las irregulares, la ascensión de las reductoras toscas y, ya al final, la aparición de las cerámicas cuidadas cocidas en atmósfera reductora. El alisado continuará siendo el acabado más frecuente, pero perderá valores frente al progresivo aumento del bruñido, que alcanza a fines de este momento su máximo valor en uno de los cortes. Abunda el espatulado como otra opción de tratamiento superficial. La presencia de ejemplares decorados es muy minoritaria.

Formalmente asistimos al aumento de la representatividad de las cazuelas carenadas de mediano tamaño (3\%) y de los recipientes carenados grandes, con idéntico porcentaje, sean éstos fuentes u ollas. Algunas de las piezas son similares a las documentadas en otros yacimientos en momentos inmediatamente previos al Bronce Pleno, como el de Guadajira (Hurtado, 1985); en tanto otras parecen preludiar o evidenciar claramente unos primeros contactos con corrientes culturales con epicentro en el Algarve portugués, que debieron desarrollarse en los últimos momentos reflejados por estos estratos. Parece ser el gran momento, entre las formas redondeadas, de los cuencos de borde entrante $(13,2 \%)$ y de los casquetes $(9,6 \%)$, que ya en la fase anterior mostraron un porcentaje comparativamente medio. La observación de las ollas globulares de mediano $(2,4 \%)$ y gran tamaño $(6 \%)$ permite comprobar que las tradiciones calcolíticas en el marco de la cerámica funcional se van difuminando muy lentamente. También disminuye el porcentaje de los vasos de paredes rectas $(14,4 \%)$, mientras los grandes bordes cóncavos, formal y funcionalmente pobres de análisis, aumentan $(27,7 \%)$. 
Si bien los estratos iniciales de La Solana no nos han ofrecido evidencias de decoración campaniforme, no dudamos de la raigambre calcolítica del grupo humano que estudiamos. Sin embargo, las producciones cerámicas, además de la dirección apuntada, nos muestran una relación directa con perfiles documentados en la tumba circular de Guadajira (Hurtado, 1985), los más característicos de los cuales, según su excavador, se intentan encuadrar en un proceso evolutivo que arranca, cuanto menos, de los contextos de las tumbas dolménicas alentejanas, y que finaliza con las formas del Bronce Pleno del Suroeste. Recuerdan enormemente formas relacionables con el mundo de Ferradeira, para las que también existe una conexión clara con las del Horizonte de las sepulturas de cúpula. Las conexiones culturales que nos manifiestan los perfiles cerámicos inmediatamente referidos parecen aludir a un momento en el cual tienen lugar sucesos tan confusos, pero posiblemente tan entrelazados, como «el canto de cisne» de la Cultura Calcolítica, el ocaso del Fenómeno Campaniforme y la gestación de las sociedades de la Edad del Bronce.

Del total de restos de industria lítica bien contextualizados y útiles para el estudio estadístico, el 58,62 $\%$ se documenta en el Horizonte Epicalcolítico, en tanto el 34,48\% lo hace en el Horizonte Solana II, por lo que, teniendo en cuenta lo escaso de la muestra y la provisionalidad con que debe tomarse todo resultado, cabría pensar en una disminución del uso de útiles líticos por parte de las gentes de La Solana, pero en modo alguno su abandono. Globalmente se trata de una industria de piedra tallada en el 51,1\% de los casos, que utiliza la cuarcita $(45,4 \%)$, el sílex $(36,3 \%)$ y el cuarzo con idéntico orden de importancia al documentado en la zona para el Calcolítico (Enríquez, 1990). Sorprende la poca representatividad de la piedra pulimentada $(6,9 \%)$, y la abundancia de un tercer grupo, muy heterogéneo, de objetos diversos $(41,8 \%)$ que incluye desde discos perforados o placas de pizarra hasta molederas.

Para esta etapa, que podría desarrollarse entre 1750/1600 y 1500 A.C., coincidiendo cronológicamente con el tradicionalmente denominado Bronce Antiguo, proponemos la denominación de Epicalcolítico, puesto que en modo alguno presenta las evidencias que han servido para caracterizar dicha fase del Bronce Antiguo en otras geografías, sino que más bien parece corresponder a una simbiosis de aspectos culturalmente adscribibles a la Edad del Bronce con elementos calificables aún como calcolíticos.

Este momento transicional parece quedar también bien reflejado en el mundo funerario, donde se produce una convivencia de manifestaciones ritológicas tales como la sepultura circular de Guadajira (Hurtado, 1985), las manifestaciones secundarias de Colada de Monte Novo (Schubart, 1971,1), los silos de la Pijotilla (Enríquez y Hurtado, 1986) y, posiblemente, los primeros enterramientos individuales en cistas. Esta aparente contemporaneidad de fórmulas funerarias tan diversas parece estar corroborada por por algunas fechaciones radiocarbónicas, como la de la segunda ocupación de Huerta Montero (con fin hacia el $3720 \pm 100$ B.P.) (Blasco y Ortiz, 1991 y 1992) o la de la segunda fase de Palacio Quemado (3570 \pm 100 B.P.) (Hurtado y Enríquez, 1992), que habría que poner en relación, en buena lógica, con un conjunto de cistas relativamente próximo.

Globalmente los cambios evidenciables en este horizonte parecen madurar una corriente iniciada cuanto menos en el Calcolítico Final, con la cual sería posible poner en conexión la progresiva consideración del individuo frente a la ancestral comunidad, visible sobre todo en los últimos pasos de una evolución observable a través de las tumbas III, I y II de La Pijotilla, la tumba circular de Guadajira y finalmente la cista documentada en el mismo lugar. También un cambio en el mundo de las creencias podría reflejar la realización de ídolos en soportes menos nobles que los de los tiempos precedentes (Enríquez y Rodríguez, e.p.), o la aparición de una divinidad masculina (Enríquez y Hurtado, 1986). La misma aparición de un hábitat estable en La Solana, hecho que supone el aprovechamiento de enclaves de cota elevada, puede dar pie a plantear el nacimiento de una auténtica jerarquización entre los asentamientos, hecho cuyo origen también pareció apuntarse a raíz del análisis espacial de yacimientos del Calcolítico Final de la zona (Enríquez, 1990, 1), cuya sociedad fue sufriendo una progresiva mayor complejidad en lo social, cultural y económico, llegando a una cierta organización territorial. 


\subsection{HORIZONTE SOLANA II}

Entre los estratos VII y IV pensamos que es posible distinguir, en función sobre todo de las cerámicas, un nuevo horizonte. Desde el marco tecnológico es un momento en el que globalmente se acentúan las tendencias vistas en los últimos instantes del horizonte anterior. Se evidencia la máxima representatividad de las cerámicas cuidadas, y un aumento porcentual de las semicuidadas. También vemos que se consolida el crecimiento de la cerámica cuidada de cocción reductora, y que continúan tanto el crecimiento de la cerámica tosca reductora como la tendencia a la baja de la irregular. Los acabados alisados ceden lugar, conservando la primacía porcentual, a los bruñidos, que alcanzan sus más importantes porcentajes, en tanto que los espatulados están presentes, pero de modo muy secundario. Constatamos la presencia de decoraciones aún con menor importancia que en momentos anteriores.

Formalmente (Figs 3 y 4) es un momento también muy fuertemente personalizado. Por una parte crece levemente el porcentaje de los cuencos carenados $(5,3 \%)$, pero sus formas evidencian una fuerte relación con el mundo de la cultura del Bronce del Suroeste I (Schubart, 1975). Gran importancia porcentual alcanzarán las cazuelas de mediano tamaño carenadas a baja o media altura $(11,9 \%)$, que podríamos considerar como elemento clave para la caracterización del período. El conjunto de formas carenadas nos apunta globalmente una fuerte conexión morfológica con el Horizonte de Atalaia, pero también señala la similitud con formas muy puntuales del mundo onubense (Del Amo, 1975), del Bajo Guadalquivir (Aubet, 1983) o de la Mancha (Molina y Nájera, 1978). Entre los redondeados, la pérdida relativa de importancia de los casquetes $(2,9 \%)$ y de los cuencos de borde entrante $(10,1 \%)$ es compensada con una buena representación de cuencos hemiesféricos $(7,1 \%)$. Las ollas globulares $(7,6 \%)$, como elementos funcionales, continúan dándose, al igual que los vasos cerrados $(6,5 \%)$ y verticales de paredes rectas $(4,1 \%)$.

En lo que a la industria lítica se refiere, con el paso al Bronce Pleno se vislumbra, por lo que respecta a las piezas tipológicas, una fuerte disminución de los dientes de hoz, y la ausencia de los cuchillos. El uso de la pizarra como materia prima para la fabricación de objetos ornamentales coincide básicamente con el Horizonte Solana II.

La industria ósea documentada se da ya desde el Horizonte Epicalcolítico, pero destaca durante el Bronce Pleno (75,5\% de los casos). Los apartados funcionales que engloban mayor número de elementos son los punzones $(30,7 \%)$ y los colgantes $(51,9 \%)$. El tipo más representado durante el Horizonte Solana II es el punzón sin base y sección cóncavo-convexa, al que acompaña durante este momento el punzón de base articular y sección cóncavo-convexa, que se documenta exclusivamente entonces. Por lo que respecta a los colgantes, la mayoría de los aparecidos en el horizonte que tratamos son discos perforados.

En el Horizonte adscrito al Bronce Pleno se documentó la pieza metálica más interesante de la excavación (Fig. 5). Se trata de una hoja triangular, ligeramente disimétrica, que presenta una longitud máxima de $20 \mathrm{~cm}$. y una anchura máxima de $7,5 \mathrm{~cm}$. Sus filos son convergentes y rectilíneos hacia el extremo distal; su unión con la zona proximal es redondeada, siendo el lado de esta extremidad convexo, y presentando dos orificios de $3 \mathrm{~mm}$. de diámetro, para remaches, estando uno de ellos obstruido, y dándose una distancia entre ambos de $4,5 \mathrm{~cm}$. No supera los $9 \mathrm{~mm}$. de grosor por el centro de la hoja, afinándose hacia los extremos. La sección es biconvexa, con una superficie más saliente que la otra en la zona próxima a la extremidad distal, tal vez por efecto de la conservación. Se trata de una pieza con algunas características peculiares de sumo interés. La relación longitud-anchura, así como su especial grosor por el centro, nos invitan a considerarla como una alabarda, aún cuando no presente la típica y definitoria nervadura central, ni pueda inscribirse en ninguno de los tres modelos (Argar-Carrapatas-Montejícar) tipificados de alabardas (Schubart, 1973, 1). En función de la personal morfología del ejemplar de La Solana, pensamos que debe tratarse de una interpretación local de este tipo de armas, hipótesis no contrastada por la 
imposibilidad total de efectuar análisis metalográficos. Ciertamente los ejemplares que se apartan de la norma tipológica no son del todo extraños en el contexto del Suroeste. Así, en Silves, Algarve, se encontró una pieza con nervadura central fuerte, a la que faltaban los orificios para los remaches, que Schubart consideró, en su día, encuadrable en el Horizonte de Ferradeira. Agotadas las posibilidades teóricas de contrastación, nos queda referirnos a la existencia de representaciones de alabardas en las losas decoradas alentejanas (Almagro Basch, 1966), cuya cronología día a día se intenta hacer más temprana (Belén, Escacena y Bozzino,1991). Desde nuestro punto de vista hay cierto parecido entre algunas de las alabardas representadas en las losas decoradas del Bajo Alentejo (Almagro Basch, 1966; Schubart, 1973, 1), especialmente la de la estela de San Juan de Negrilhos, y el ejemplar de La Solana. Como todos sabemos, los tipos representados en las losas jamás han podido ser identificados con tipos reales, planteándose con ello ciertos interrogantes.

Posiblemente la conclusión más interesante a que nos conducen las relaciones culturales a las cuales aluden los análisis de los artefactos documentados es la magnífica salud que goza durante Plena Edad del Bronce la ruta natural que el río Guadiana abre con su paso. Ya Schubart (1974) señaló en su día la importancia del ramal del Guadiana como vínculo entre el Algarve y la provincia de Badajoz, pero el estado de la investigación impidió en principio definir, o esbozar al menos, la naturaleza de las relaciones entre el centro y esta zona periférica del Bronce del Suroeste. Hoy día poseemos más elementos de juicio para intentar dibujar dicha relación, gracias no sólo a la observación de las manifestaciones hasta hoy conocidas del Bronce Pleno en la Baja Extremadura, sino también a las posibilidades que nos ofrece la observación de las bases subsistenciales de la Solana, que centrarán nuestra atención en un próximo apartado.

\subsection{HORIZONTE SOLANA III}

Entre los estratos III y I se desarrolla el momento peor conocido de la estratigrafía, tal vez por ser el más afectado por las labores agrícolas, o por corresponder no a una ocupación real de la zona, sino a la deposición de materiales rodados de la parte superior de la ladera. La imagen del momento, mal definida en la tecnología, pobre tipológicamente, y sólo imaginable a través de piezas aisladas (Fig 6), debe completarse con la que hasta el momento han ofrecido los estudios realizados por Enríquez (1988; 1990,2; 1991) sobre hallazgos de superficie procedentes del cerro del castillo de Alange.

Tal vez la intervención estratigráfica de 1987 en La Solana ha servido para aclarar una de las cuestiones planteadas: la posible relación genética entre manifestaciones decorativas más antiguas (la técnica de boquique documentada en un posible Neolítico Final, las distintas técnicas del Campaniforme, etc.) y las recogidas de la superficie del Castillo de Alange (Enríquez, 1988). No se constata en la estratigrafía de La Solana un vínculo fuerte y constante entre las manifestaciones campaniformes (ausentes por el momento) y las decoraciones tipo boquique, por lo que, como en otras zonas, parece rebatirse esa conexión que sí parece darse en la Meseta. Este hecho conlleva necesariamente la búsqueda de una interrelación a escala geográfica mayor, y, como paso siguiente, la aparición de nuevas perspectivas de explicación del proceso histórico. Ya Enríquez en su momento señaló la posibilidad de relacionar los materiales de su estudio con los del Complejo Cultural de Cogotas I (Fernández-Posse, 1986). Hoy, a la vista de la estratigrafía de la Solana, tal intuición parece confirmarse, suponiendo por lo tanto Alange un testigo más que parece querer reflejar ese fenómeno, tan discutido últimamente (Pellicer, 1989), de expansión de grupos meseteños hacia el sur peninsular. La historiografía de los últimos años contempla en el Sureste peninsular y en Andalucía la existencia de una etapa oscura a caballo entre el Bronce Pleno y el Bronce Reciente o Final. Tal momento ha sido bautizado como Bronce Tardío (Molina, 1978), y pese a poder diferenciarse claramente del Bronce 
Pleno precedente, y estar relativamente bien personalizado en la zona argárica y en su periferia inmediata, conceptualmente no está consolidado en otras regiones como Andalucía Occidental. Las dificultades para su aceptación vienen conferidas por distintas causas, entre las que destacamos dos. Por una parte el fenómeno afecta a zonas geográficas diferenciables a niveles ambientales e históricos, donde, pese a tener lugar en una banda de tiempo aproximadamente coincidente, se recoge con una terminología distinta (Martín de la Cruz, 1989). Por otra parte, es un hecho que necesariamente se yuxtapone a otros sucesos que hay que tener en cuenta a la hora de definir el proceso de formación del mundo tartésico, por lo que la controversia al respecto está asegurada. Pese a existir una postura más o menos consensuada de que entre el Bronce Pleno y el Bronce Final Antiguo se aprecia globalmente un «paréntesis cultural», una curiosa «discontinuidad» entre el Bronce Pleno y el Bronce Final, leida en Setefilla en términos «transicionales» (Aubet, 1983), y originada, en el fondo, en función del vacío de datos arqueológicos relativos al período comprendido entre el 1200 y el 900 A.C. (Aubet, 1986), no existe acuerdo a la hora de caracterizarlo. Dejando entre paréntesis su relación con el problema tartésico, creemos de interés más inmediato referirnos a la problemática de las cerámicas en cuestión. Muy puntuales evidencias llevan a ciertos investigadores (Caro, 1989) a defender en ese paréntesis más que por una aportación meseteña, el origen de los tipos cerámicos característicos en la propia Andalucía Occidental, en el seno de sociedades «postargáricas» continuadoras de tradiciones neolíticas, cuyas influencias serían decisivas para la cristalización de dichas decoraciones en la Meseta y Extremadura.

No podemos, desde la estratigrafía de La Solana, pretender ni siquiera un posicionamiento sólido en uno u otro sentido, máxime si los elementos materiales en cuestión no están bien estratificados, pero consideramos por el momento más viable la hipótesis de la llegada de estos tipos cerámicos por influencia meseteña. Por otra parte, el interés permanente de un punto estratégico como es el Cerro del Castillo de Alange, impide valorar a través de su estratigrafía cuestiones como la decadencia o el auge del poblamiento, de la economía, de las costumbres, etc. que deben meditarse conjuntamente a la hora de defender un «paréntesis cultural»... y más aún con una información exclusivamente estratigráfica. Nos encontramos aún muy lejos de poder caracterizar en nuestra zona ese escurridizo y ambiguo Bronce Tardío, entre otras razones porque los momentos de comparación obligada con él, cuales son el Bronce Pleno y el Bronce Final, no están aún suficientemente conocidos.

Una valoración global del poblamiento, en función de la localización de los hallazgos en la Baja Extremadura, concede al Bronce Final, según Enríquez (1991), la ocupación de puntos estratégicos claves en el control de las vías que cruzan el Guadiana, en áreas de excelente capacidad agrícola. Esta rearticulación territorial y de intereses económicos, viarios y estratégicos, en función de los rasgos de la cultura material, y del único punto cronológico referencial (800 A.C. del comienzo de la Fase I, del Bronce Final, de Medellín), podría ponerse en relación con el efecto expansivo que la Cultura Tartésica, constituida plenamente como tal a raíz de la eclosión del siglo IX A.C., tiene en toda su periferia.

Desde esta hipótesis, el Cerro del Castillo de Alange se convierte en un punto en el mapa con una problemática específica, ya que se trata del único enclave estratégico, por el momento, que, presentando cerámicas lisas y decoradas adscritas al Bronce Final, parece presentar restos remontables a momentos del Bronce Pleno. Si una lectura global del panorama pacense invita a considerar la vertebración del Bronce Final como claramente diferenciable de la cultura del Bronce Pleno, la observación de la ocupación continuada de La Solana supone una pincelada de color, en principio distinto, a la monocromía dominante a nivel general.

Durante el Bronce Final parece inaugurarse una geoestrategia en función de la cual los vados juegan un papel importante en la comunicación norte-sur (futura Vía de la Plata), que alcanzará su cénit con la romanización, momento a partir del cual, con la creación del puente de Augusta Emérita (Alvarez, 1981), el papel de Alange como cruce de caminos parece eclipsarse. 


\section{LAS BASES SUBSISTENCIALES}

Si tenemos en cuenta que los materiales procedentes de los ajuares documentados en el conjunto de las cistas de la Baja Extremadura (Gil-Mascarell y otros, 1986) están claramente en conexión con los procedentes del Horizonte Solana II, podemos intuir, al margen de cuestiones socio-religiosas, como el hecho de que durante el Bronce Pleno se pueda producir la generalización del ritual funerario de la inhumación individual, es posible extraer hipótesis de trabajo sobre la economía de la época. Del análisis espacial de dichas manifestaciones funerarias, además de su problemática relación con poblados cuyos últimos niveles bien conservados parecen ser epicalcolíticos, se desprende que parecen reflejar una intensa ocupación de las márgenes del Matachel y sus afluentes, reflejo indiscutible del aprovechamiento agroganadero de estos fértiles valles.

El análisis del área de captación de recursos de la Solana ha esbozado una serie de tendencias que la información procedente de la excavación ha respaldado categoricamente. De las posibilidades en primer término agrícolas, y en segundo lugar ganaderas, han dado cumplida cuenta los artefactos, ecofactos y restos óseos estudiados.

El elevado número de dientes de hoz con pátina de uso, y, sobre todo, la abundancia de piedras de molino nos hacen pensar en un cultivo de cereales, que debió desarrollarse para alimentar una población en principio abundante. El hallazgo de un buen número de semillas de «Vicia faba vard. minor» (habines) asociadas posiblemente a un recipiente de almacén, en un estrato del Horizonte Solana II, nos está aludiendo a la manipulación por parte del hombre de esta especie, especialmente indicada para terrenos de aluvión y suelos ligeros y húmedos, tales como los que rodean el curso del Matachel y sus afluentes. Desde el punto de vista de la ecología es preciso resaltar la perfecta conjunción entre el cultivo de esta especie y la conservación de la riqueza del suelo. Esta planta es susceptible de aprovechamiento por parte del hombre cuando es joven, y constituye un excelente pienso para el ganado cuando ha madurado (Agradecemos el análisis y comentario de las muestras a D. A. Machuca Calderón).

El desarrollo de actividades ganaderas, intuido a partir de la información precedente se ha visto corroborado con el análisis de los restos óseos exhumados, llevados a cabo por D. P. Castaños Ugarte. Aún teniendo en cuenta la escasez de la muestra, parece evidente que para la economía de estos grupos humanos, la ganadería jugó un papel mucho más importante que la actividad meramente cinegética, según se desprende del predominio de las especies domésticas sobre las salvajes (Figs 7 y 8). Dentro de las primeras se observa un equilibrio entre las cabañas de bovino, ovicaprino y cerdo, muy común para la época que estudiamos en el suroeste de la península (Castaños, 1991). Las ausencias más significativas son las del perro y el caballo. El seguimiento del número de restos y del número mínimo de individuos documentados en cada horizonte no parece señalar el predominio de alguna de las cabañas domésticas sobre las demás. Lo que sí parece reflejarse muy claramente es una actitud común de cara al aprovechamiento de los recursos ganaderos. Así, por lo que respecta al bovino, el predominio de los ejemplares adultos frente a los jóvenes alude a un modelo de aprovechamiento de carácter secundario, interesando frente al mero aprovechamiento cárnico la producción de leche y la utilización de la fuerza mecánica, probablemente en actividades agrícolas. Este modelo de aprovechamiento relativamente equilibrado se constata también en el ganado porcino, y muy especialmente en el ovicaprino, donde mientras unos ejemplares se destinan a la producción de carne, otros se conservan hasta una edad adulta o senil, como vías para la obtención de productos secundarios como lana o leche. En este sentido la documentación de punzones y de queseras aluden al desarrollo de trabajos textiles y a la producción de queso. La conservación hasta edad adulta tiene lugar fundamentalmente entre las hembras, hecho que además de con su potencial lácteo debe ponerse en relación con el interés por la reproducción de la especie. 
Además de la caza, en principio con importancia secundaria, de conejos, liebres, jabalíes y ciervos, se constata también el posible aprovechamiento de la pesca, en función de útiles que pueden interpretarse como pesas de red, y la recolección de malacofauna.

La peculiar morfología de algunos útiles metálicos, tales como la alabarda del Horizonte Solana II, hallados en el proceso de excavación, nos invitaba a plantear como hipótesis de trabajo la posibilidad del desarrollo de actividades metalúrgicas a escala local. Tal supuesto estaba respaldado por la importancia que ya desde el Calcolítico parece tener ésta en la Cuenca Media del Guadiana. Previsiblemente la solución al problema llegaría con el análisis de las muestras de escoria recogidas en la excavación. Hasta el presente sólo se ha llevado a cabo el análisis de dos de las muestras, cuya interpretación, dado el protagonismo del hierro entre sus determinaciones, es tremendamente problemática. Hasta que no se lleven a cabo nuevos análisis el problema no quedará zanjado. Por el momento hemos intentado sopesar las posibilidades de la explotación del cobre en nuestra zona. Aunque actualmente las mineralizaciones de cobre conocidas en Extremadura son numerosas, la pequeñez de las manifestaciones, su baja ley y el carácter filoniano de las mismas hacen poco atractiva su posible explotación. Aún así estudios técnicos recientes (Florido, 1987) han defendido que Extremadura era posiblemente autosuficiente en cobre, para la franja de tiempo en que nos movemos, por sus reservas del sur, junto a los yacimientos de Huelva.

Si bien las reflexiones anteriores pueden arrojar alguna luz sobre las relaciones económicas, las relaciones sociales existentes entre las personas que viven en los valles y las que viven en cotas más altas son hoy por hoy una incógnita, que, esperemos, puedan resolver futuros trabajos.

\section{RECAPITULACIÓN}

El yacimiento de la Solana del Castillo de Alange constituye hasta el momento, uno de los escasos testigos capaces de ofrecernos en su desarrollo secuencial una imagen de la actividad humana en la Cuenca Media del Guadiana durante un momento tan mal conocido como es el segundo milenio A.C. (Fig 9).

El estudio de la cultura material ha permitido articular el yacimiento en tres horizontes que consideramos Epicalcolítico, de Bronce Medio y de Bronce Tardío-Final respectivamente.

Durante los momentos más antiguos de La Solana es posible apreciar como la extinción del mundo calcolítico se produce muy lentamente y sin sobresaltos, tiñendo de sí a las emergentes sociedades de la Edad del Bronce. Durante un momento cronológico paralelo al tradicional Bronce Antiguo, nuestra región, en la que la incidencia del Fenómeno Campaniforme no pareció ser determinante, tamiza los incipientes elementos de cultura material que nos hablan de su inclusión en el mundo del Bronce del Suroeste, con los últimos rescoldos de calcolitización, qụe se concretan no sólo en la repetición de formas cerámicas antiguas, sino también en una continuidad en los modos de vida ancestrales.

Durante el Bronce Pleno, nuestra región ofrece el aspecto de una zona periférica de la Cultura del Bronce del Suroeste, con lo que ello supone de matización de influencias procedentes de la zona nuclear, y de pervivencia en unas tradiciones hondamente arraigadas.La documentación de este horizonte constituye un hecho novedoso dentro de la investigación de la Prehistoria Reciente de la Cuenca Media del Guadiana, no sólo por el interés de su ergología, sino también por la posibilidad de acercarnos al análisis de sus bases subsistenciales.

El Bronce Tardío-Final del Cerro del Castillo de Alange ya ha ocupado el interés de la investigación en ocasiones anteriores. El análisis de las piezas aparecidas en la intervención de 1987 no ha ofrecido nuevas vías interpretativas, sino más bien ha subrayado las conclusiones a que dichos estudios precedentes 
llegaron. La naturaleza fronteriza, tantas veces señalada, de Extremadura, posibilita que en ella se conjuguen elementos del núcleo meseteño de Cogotas $\mathrm{I}$, con influjos portugueses y meridionales, acrisolándose así una realidad que acusará también en torno al siglo IX A.C. la vertebración del mundo tartésico.

El panorama que se ha tratado de esbozar en el presente artículo, al desprenderse exclusivamente de los resultados de una intervención de urgencia, es totalmente provisional; pero ello no impide apreciar que posiblemente el yacimiento de la Solana del Castillo de Alange se convierte hoy por hoy una de las máximas esperanzas de cara a resolver algunos de los problemas aún existentes de cara al conocimiento de la Prehistoria Reciente en la Cuenca Media del Guadiana. Esperamos que futuros trabajos posibiliten acceder más claramente a ese segundo milenio A.C. que tan oscuro se nos muestra no sólo en nuestra región, sino también en todo el Suroeste peninsular.

\section{BIBLIOGRAFÍA}

ÁLVAREZ MARTÍNEZ, J.M. (1981) El puente y el urbanismo romano de Augusta Emerita. Madrid ÁLVAREZ ROJAS, A. y GIL MONTES, J. (1988) «Aproximación al estudio de las vías de comunicación en el primer milenio antes de Cristo en Extremadura». Trabajos de Prehistoria ${ }^{\circ} 45$.

ALMAGRO BASCH, M. (1966) «Las estelas decoradas del S.W. peninsular». Bibliotheca Praehistórica Hispánica Vol. VIII. Madrid.

AUBET SEMLER, M.E. (1981) «Sepulturas de la Edad del Bronce en la Mesa de Setefilla». Madrider Mitteilungen $\mathbf{n}^{\circ} 22$.

(1983) «La Mesa de Setefilla, Lora del Río. Excavaciones Arqueológicas en España n 122.

(1986) «Horizonte Cultural Protohistórico». Tartessos. Revista de Arqueología.

AUBET, M.E. y SERNA, M.R. (1981) «Una sepultura de la Edad del Bronce en Setefilla». Trabajos de Prehistoria $n^{\circ} 38$.

BELÉN, M. ESCACENA, J.L. y BOZZINO, M.I. (1991) «El mundo funerario del Bronce Final en la Fachada Atlántica de la Península Ibérica. Análisis de la documentación.» Trabajos de Prehistoria»n 48.

BLASCO RODRÍGUEZ, F. Y ORTIZ ALESON, M. (1991) «Avance al estudio del sepulcro de corredor de «Huerta Montero» (Almendralejo, Badajoz)». Stvdia Zamorensia ${ }^{\circ}$ XII.

(1992) «Trabajos arqueológicos en «Huerta Montero». Almendralejo, Badajoz». I Jornadas de Prehistoria y Arqueología en Extremadura (1986-1990). Extremadura Arqueológica nII. MéridaCáceres.

CALERO CARRETERO, J.A. y OTROS. (1988) «Cuarta y quinta campañas de excavaciones arqueológicas en Alange (1987-1988)». XVII Coloquios Históricos de Extremadura. Trujillo.

CALERO, J.A. y MARQUEZ, A. (1992) «Prospecciones, sondeos y excavaciones en Alange». I Jornadas de Prehistoria y Arqueología en Extremadura (1986-1990). Extremadura Arqueológica noII. MéridaCáceres.

CARO BELLIDO, A. (1989) «Consideraciones sobre el Bronce Antiguo y Medio en el Bajo Guadalquivir». Tartessos. Sabadell.

CASTAÑO UGARTE, P.M. (1991) «Animales domésticos y salvajes en Extremadura. Origen y evolución». Revista de Estudios Extremeños. Tomo XLVII. nI.

CERRILLOMARTÍN DECÁCERES, E. (1985) «El tiempo pre y protohistórico». Historia de Extremadura I. Badajoz. 
DEL AMO, M. (1975) «Enterramientos en cista en la provincia de Huelva». Huelva: Prehistoria y Antigüedad. Madrid.

ENRIQUEZ NAVASCUES J.J. (1988) «Algunas cerámicas decoradas del castillo de Alange (Badajoz)». Homenaje a Samuel de los Santos.

$(1990,1)$ «El Calcolítico o Edad del Cobre de la cuenca extremeña del Guadiana». Publicaciones del Museo Arqueológico Provincial de Badajoz, n². Badajoz.

$(1990,2)$ «El Bronce Final extremeñ o y su relación con la cultura tartésica». La cultura tartésica y Extremadura. Cuadernos Emeritenses nº 2 . Mérida.

(1991) «Sobre algunos poblados del Bronce Final de la Provincia de Badajoz». Norba Revista de Historia $\mathbf{n}^{\circ} 10$. Cáceres.

ENRIQUEZ, J.J. y HURTADO, V. (1986) «Prehistoria y Protohistoria». Historia de la Baja Extremadura I. Badajoz.

ENRIQUEZ, J.J. y RODRÍGUEZ, A. (E.P.) «Algunos ídolos en barro cocido y hueso de la Baja Extremadura». I Congreso Internacional sobre Religiones Prehistóricas en la Península Ibérica.

ESCACENA, J.L. y DE FRUTOS, G. (1985) «Estratigrafía de la Edad del Bronce en el Monte Berrueco (Medina Sidonia, Cádiz). Noticiario Arqueológico Hispano ${ }^{\circ} 24$.

(1986) «El tránsito del Calcolítico al Bronce a través del Monte Berrueco, de Medina Sidonia (Cádiz)». Trabajos de Prehistoria ${ }^{\circ} 43$.

FERNÁNDEZ-POSSE Y DE ARNAIZ, M.D. (1986) «La Cultura de Cogotas I». Homenaje a Luis Siret. Sevilla.

FLORIDO LARAÑA, P. (dir.) (1987) La minería en Extremadura. Consejería de Industria y Energía de la Junta de Extremadura

GIL-MASCARELL BOSCA, M. y OTROS. (1986) «Enterramientos en cista de la Edad del Bronce en la Baja Extremadura». Saguntum n²0.

GIL-MASCARELL, M. y RODRÍGUEZ, A. $(1985,1)$ «Un enterramiento en cista en Villafranca de los Barros (Badajoz)». Homenaje a Beltrán.

$(1985,2)$ «El yacimiento calcolítico de Los Cortinales en Villafranca de los Barros (Badajoz)». Arch. de Prehistoria Levantina. Homenaje a Fletcher.

(1988) «»Los Cortinales», un yacimiento calcolítico en Villafranca de los Barros (Badajoz)». Extremadura Arqueológica n ${ }^{\circ}$.

GUERRA DELGADO, A. y MONTURIOL, F. (1968) Explicación del Mapa Provincial de Suelos (Badajoz). Madrid.

HURTADO PÉREZ, V. (1985) «La excavación de una sepultura circular de la Edad del Bronce en Guadajira (Badajoz)». Homenaje a Cánovas Pesini. Badajoz.

(1991) «Análisis y definición de los procesos culturales durante el segundo milenio en el suroeste peninsular». IV Jornadas de Arqueología Andaluza.

HURTADO, V. y ENRIQUEZ, J.J. (1992) «Excavaciones en Palacio Quemado (Alange, Badajoz). Informe Preliminar. I Jornadas de Prehistoria y Arqueología en Extremadura (1986-1990). Extremadura Arqueológica ñII. Mérida-Cáceres.

JIMÉNEZ ÁVILA, F.J. y MUÑOZ HIDALGO, D. (1991) «Aportaciones al conocimiento del Calcolítico de la Cuenca Media del Guadiana: la comarca de Zafra». Norba Revista de Historia ${ }^{\circ} 10$. Cáceres.

MARTÍN DE LA CRUZ, J.C. (1989) «El Bronce en el Valle Medio del Guadalquivir». Tartessos. Sabadell.

MOLINA GONZÁLEZ, F. (1978) «Definición y sistematización del Bronce Tardío y Final en el Sudeste de la Península Ibérica». Cuadernos de Prehistoria de la Universidad de Granada nºIII. 
MOLINA, F. y NAJERA, T (1978) «Die motillas von Azuer und Los Palacios». Madrider Mitteilungen $\mathrm{n}^{\circ} 19$.

NAJERA, T. y OTROS (1981) «La motilla de Azuer (Daimiel, Ciudad Real). CampaÑa de 1981». Cuadernos de Prehistoria de la Universidad de Granada n ${ }^{\circ} 6$.

NIETO GALLO, G. y SÁNCHEZ MESEGUER, J. (1980) «El Cerro de La Encantada (Granátula de Calatrava, Ciudad Real)». Excavaciones Arqueológicas en EspaÑa n 113.

PELLICER CATALÁN,M. (1989) «El Bronce Reciente y los inicios del Hierroen Andalucía Occidental». Tartessos. Sabadell.

RIVERO DE LA HIGUERA, M. (1991) «Dos vasos del Bronce del Sudoeste en la colección del Marqués de la Encomienda (Almendralejo, Badajoz)». Stvdia Zamorensia n ${ }^{\circ} X I I$.

RODRÍGUEZ DÍAZ, A. (1986) Arqueología de Tierra de Barros. Zafra.

SCHUBART, H. (1968) «Estratigrafía horizontal de Atalaia. Una contribución a la cronología de la Edad del Bronce en el Sudoeste de la Península Ibérica. XI Congreso Nacional de Arqueología.

$(1971,1)$ «Tumbas megalíticas con enterramientos secundarios de la Edad del Bronce de Colada de Monte Nuevo de Olivenza». XII Congreso Nacional de Arqueología.

$(1971,2)$ «O Horizonte de Ferradeira. Sepulturas do Eneolítico final no Sudoeste da Península Ibérica». Revista de Guimaraes 71 3/4.

$(1973,1)$ «Las alabardas tipo Montejícar». Estudios dedicados a Luis Pericot. Barcelona.

(1974) «La Cultura del Bronce del Suroeste peninsular. Distribución y definición». Miscelánea Arqueológica II.

(1975) Die Kultur der Bronzezeit im Südwesten der Iberische Halbinsel. Berlín.

TAVARES DA SILVA, C. y SOARES, J. (1981) Prehistoria da Area de Sines. Lisboa.

VARELA GOMES, M. (1986) «A necropole da Vinha do Casao (Villamoura, Algarve) no contexto da Idade do Bronce do Sudoeste peninsular». Trabalhos de Arqueología 02. 


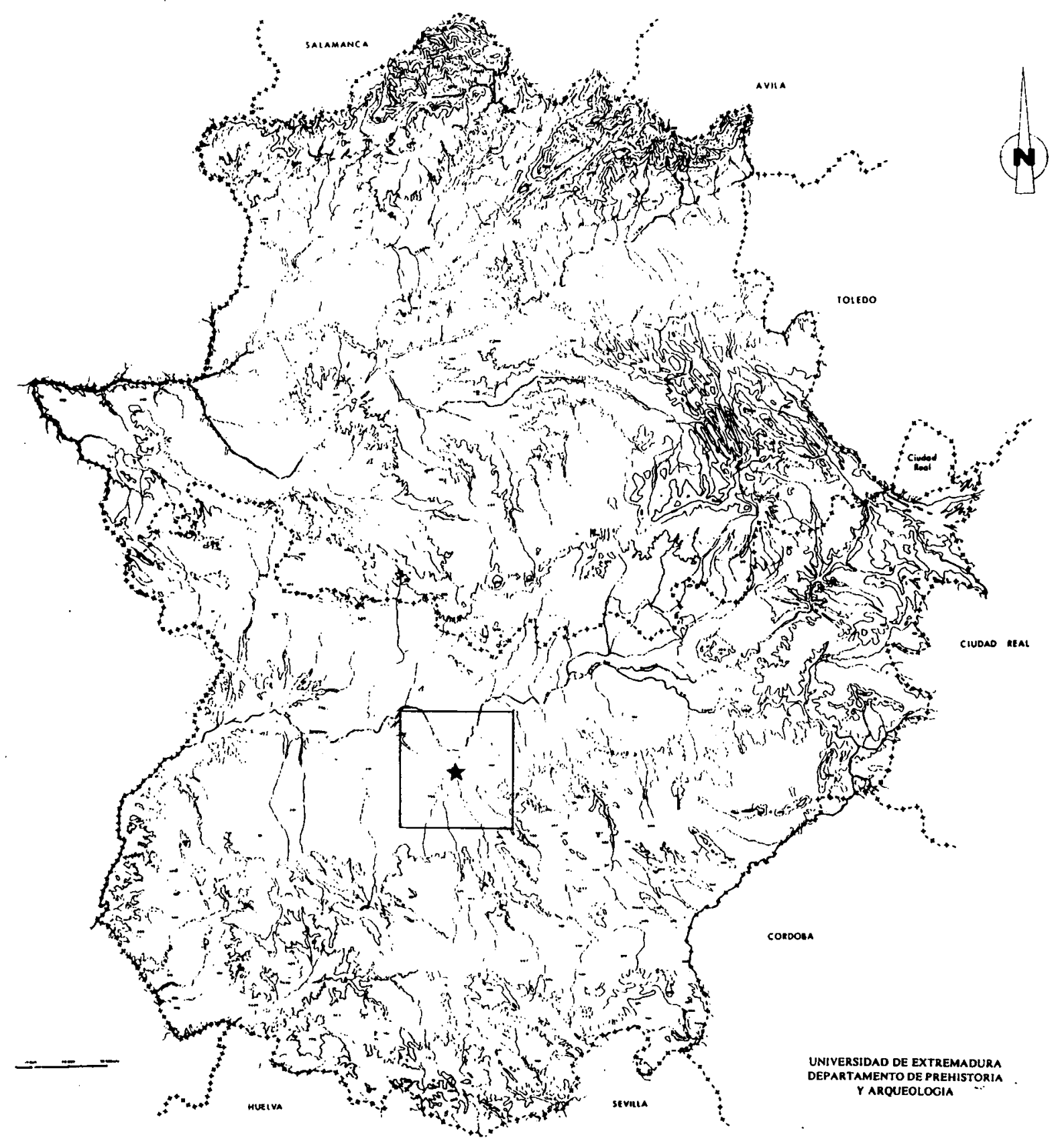

FIGURA 1: Situación del yacimiento de La Solana (Alange). 

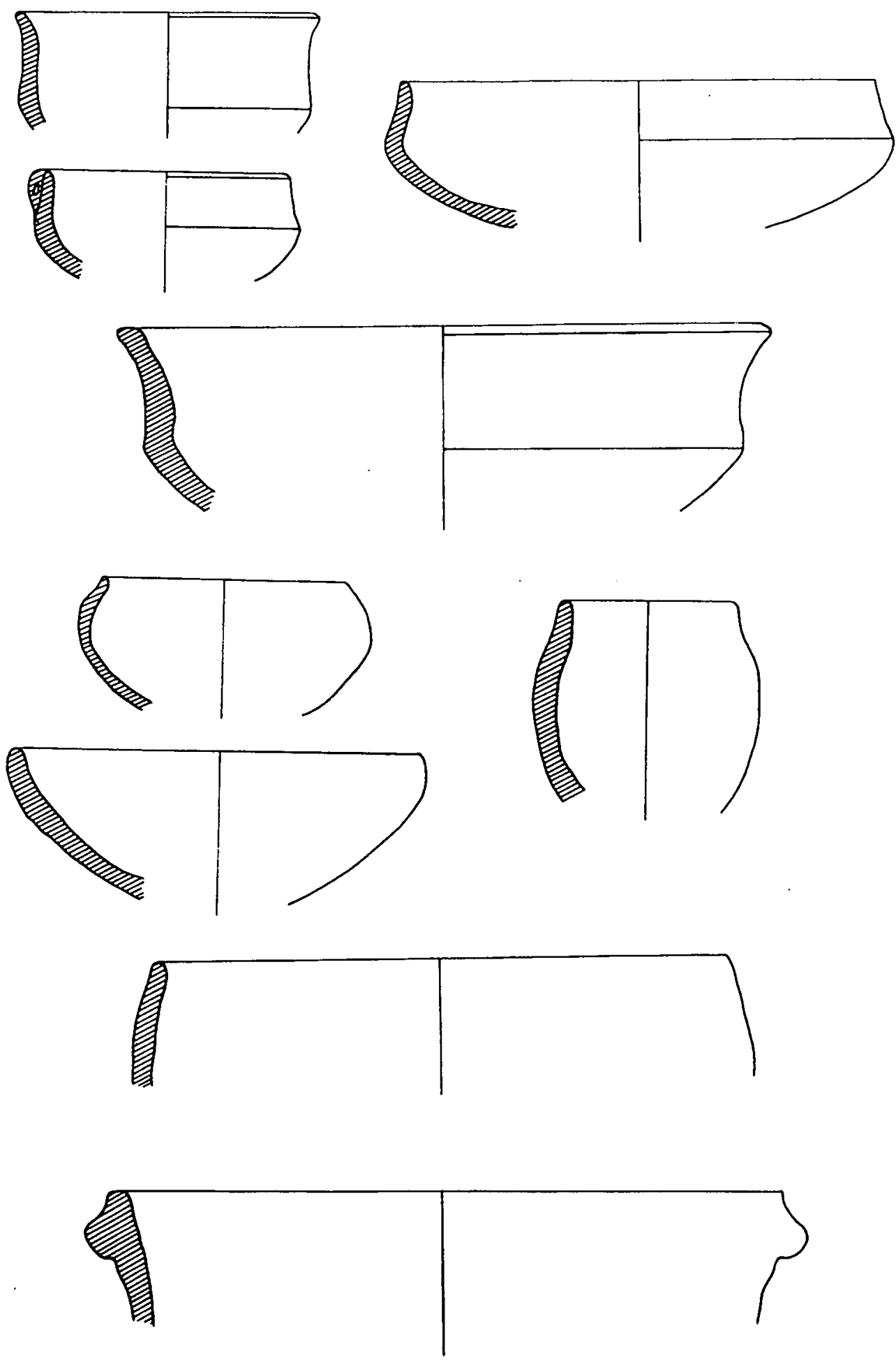

FIGURA 2: Algunas formas representativas del Horizonte Solana I. 

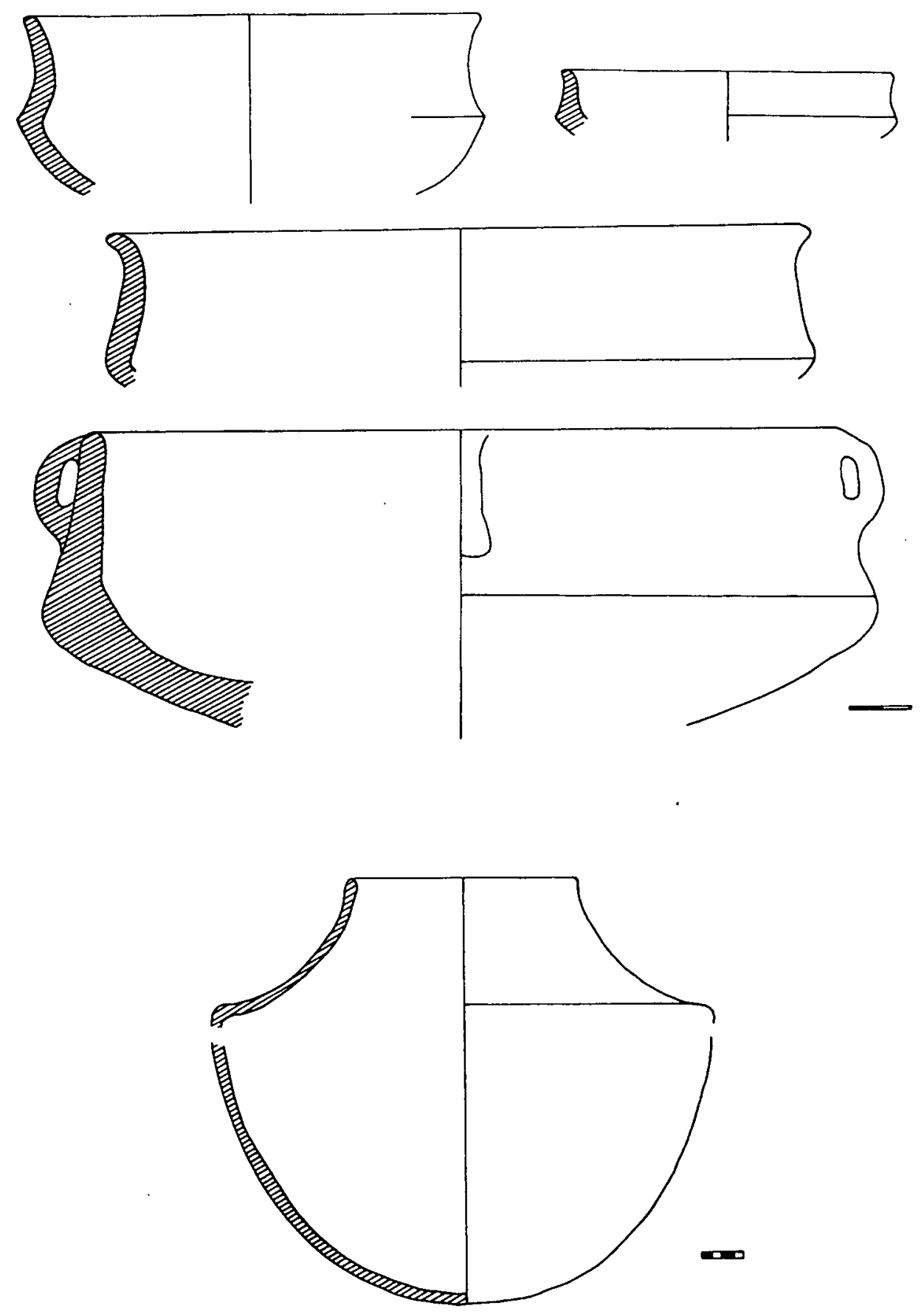

FIGURA 3: Algunas formas representativas del Horizonte Solana II. 

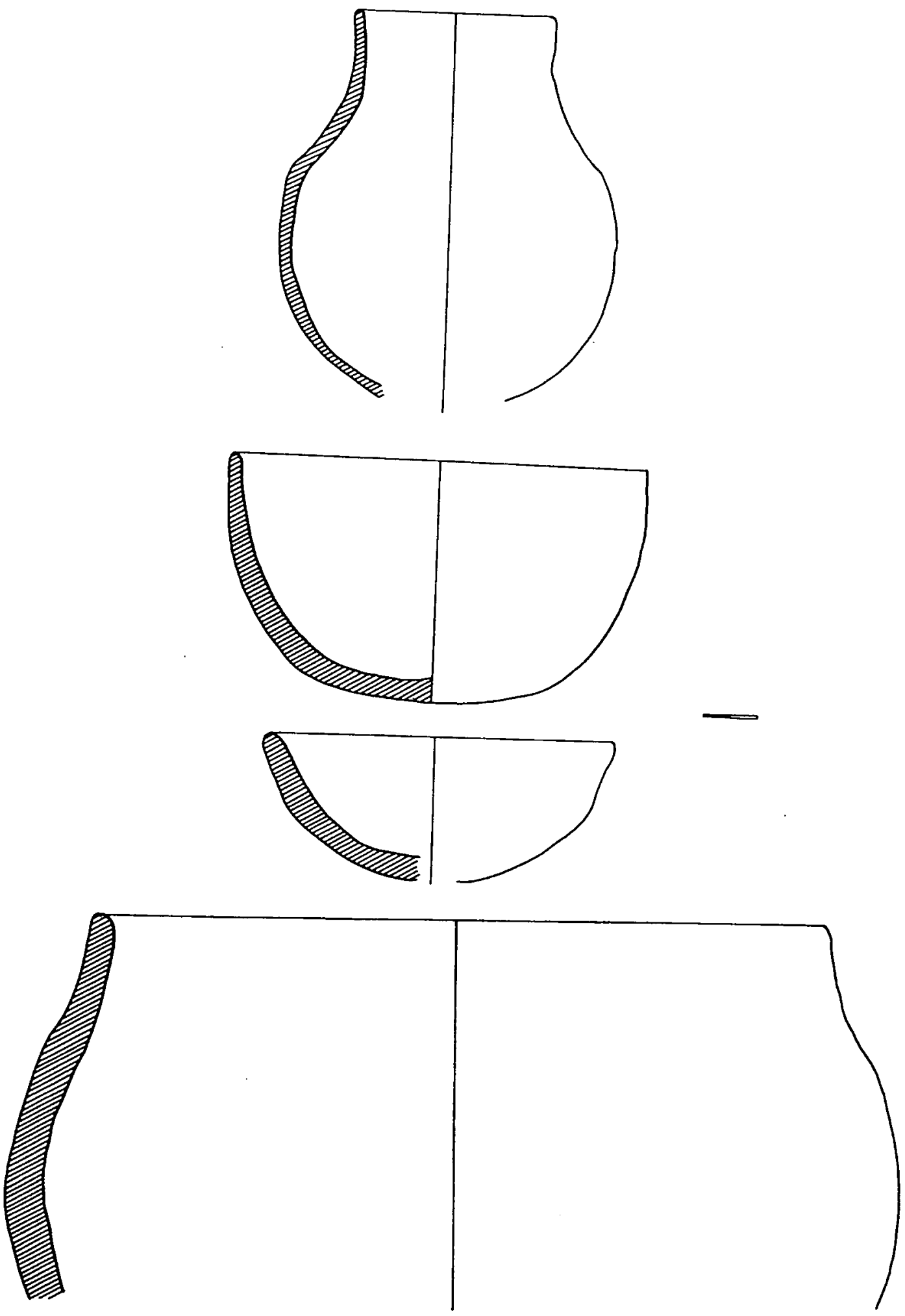

FIGURA 4: Algunas formas representativas del Horizonte Solana II. 
DEPOSITO MAPB 799

verusilu MAPB 799

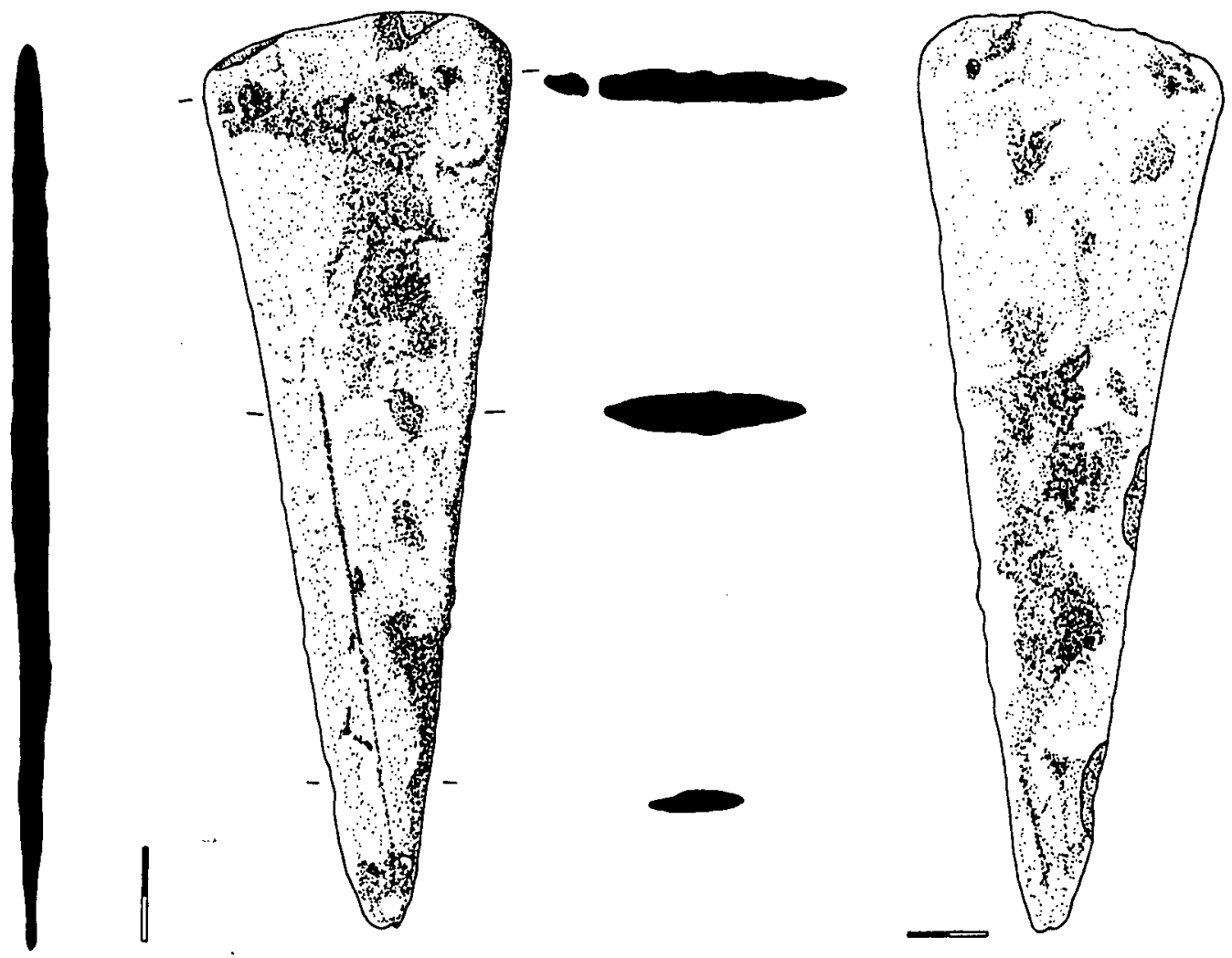

FIGURA 5: Alabarda (Horizonte Solana II). 

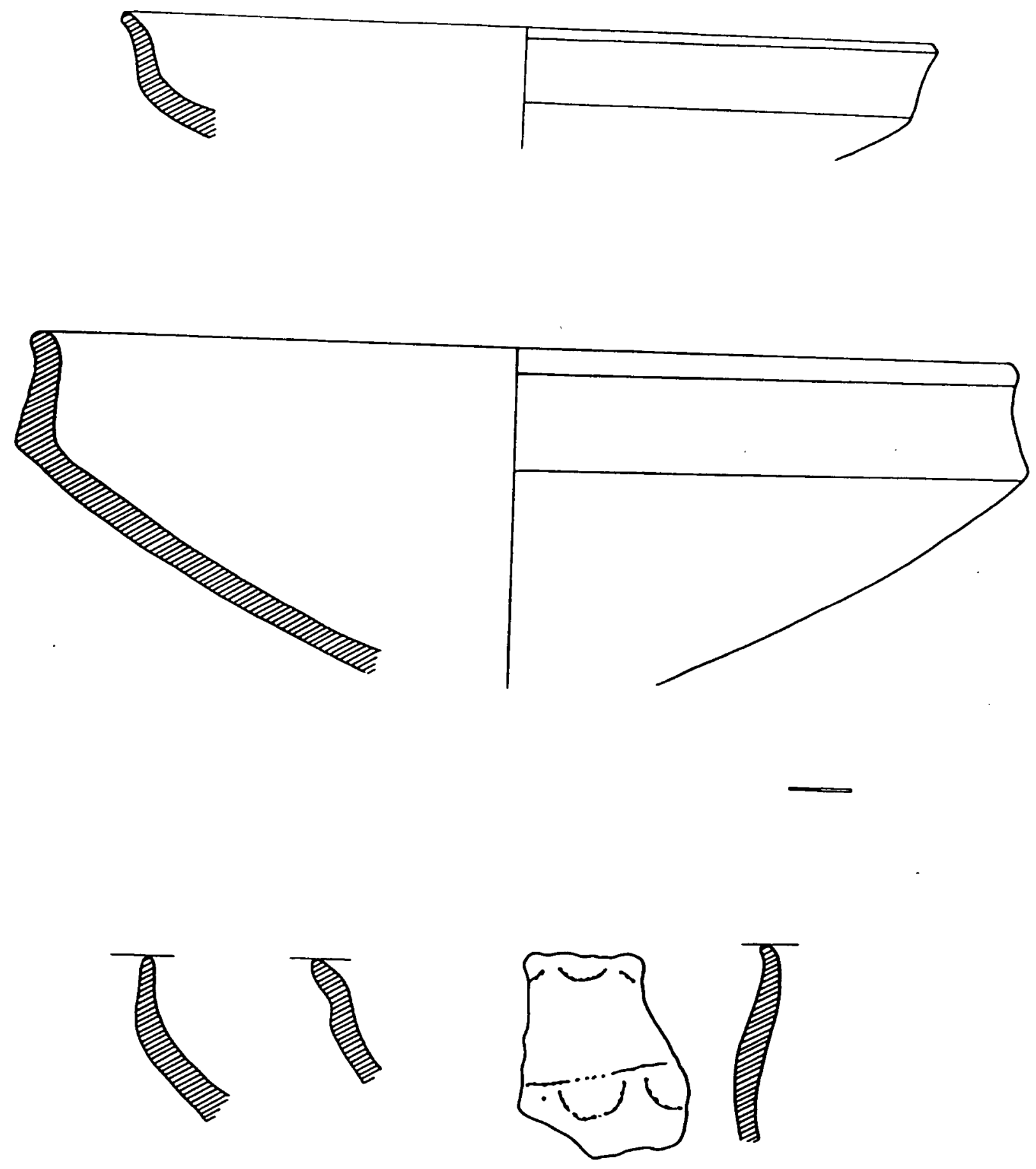

FIGURA 6: Algunas formas representativas del Horizonte Solana III. 


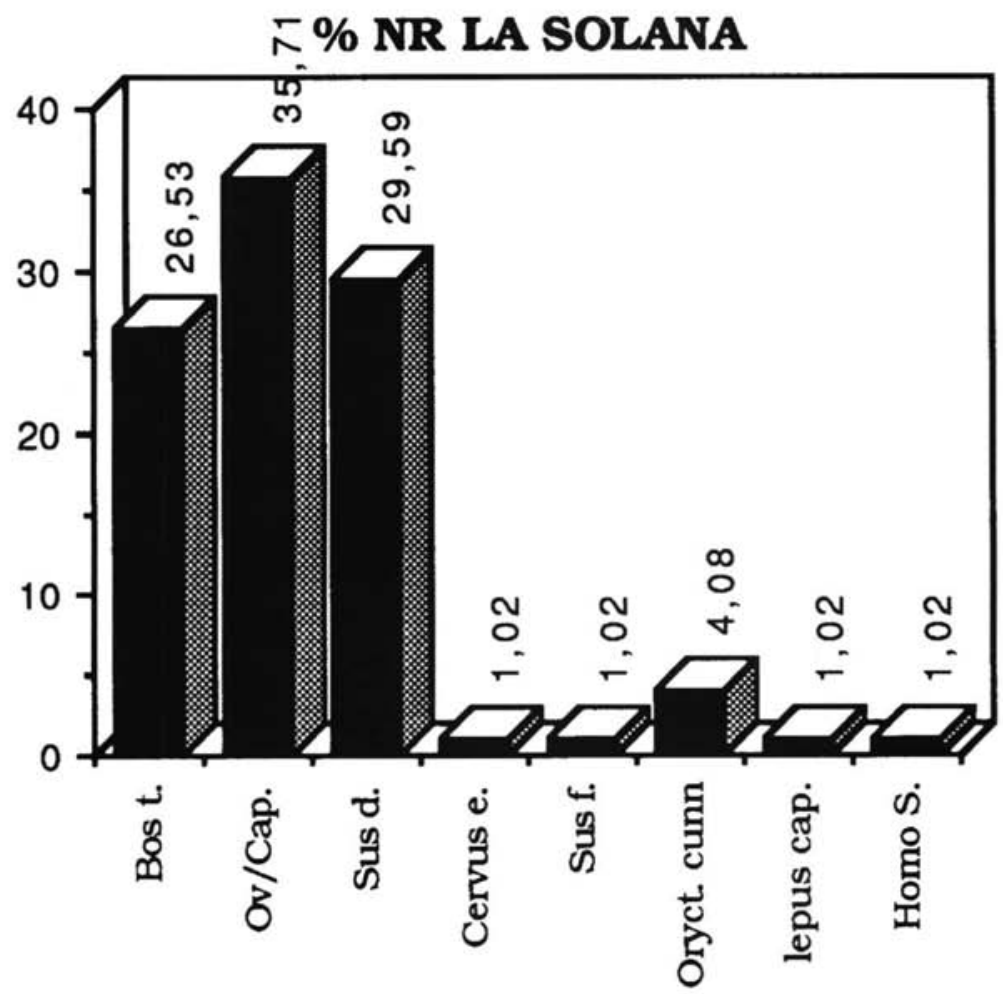

FIGURA 7: Histograma de la fauna de La Solana. 

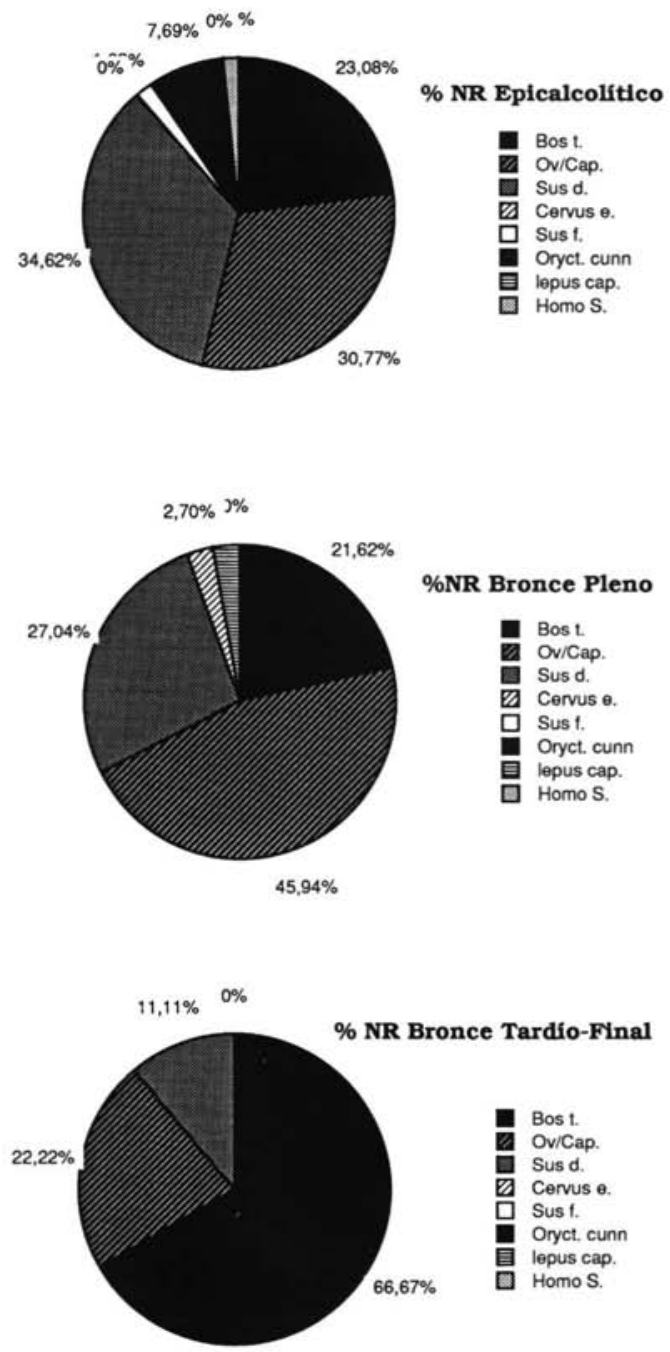

FIGURA 8: Comportamientos porcentuales de la fauna en los distintos horizontes. 


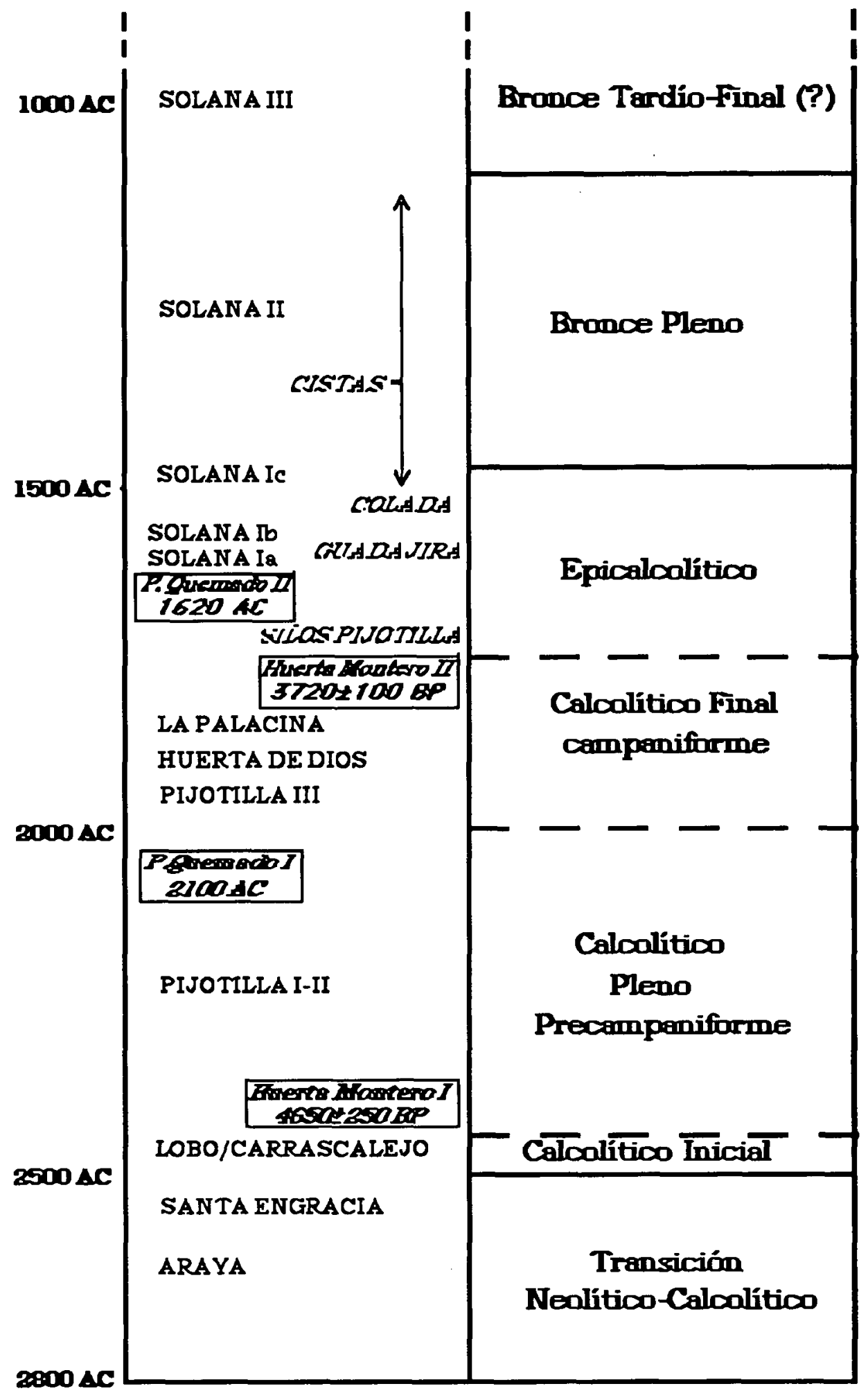

FIGURA 9: Secuencia de la Prehistoria Reciente en la Cuenca Media del Guadiana. 